\title{
Uma construção coletiva de encontros e encantamentos
}

\author{
CARLA LOPES
}

IRENE PIÑEIRO

Maria Eleonora L. RabÊLlo *

\section{A CASA... e como tudo acontece.}

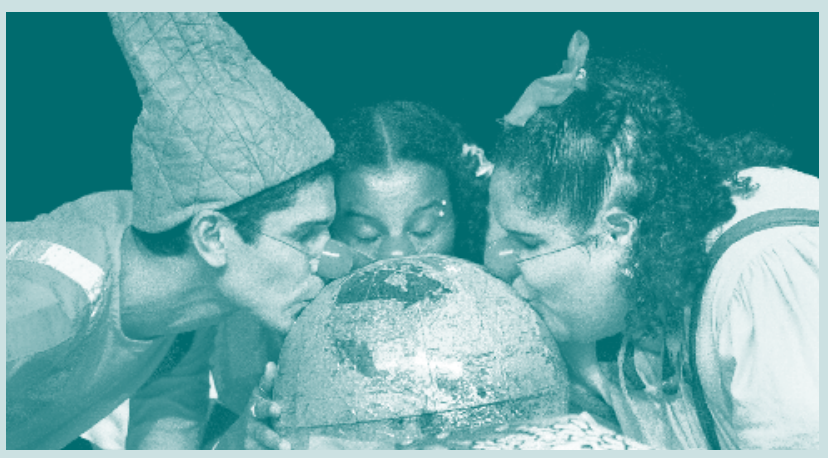

O Centro de Referência Integral de Adolescentes - CRIA é uma organização não governamental sediada no Pelourinho, na cidade de Salvador, Bahia. A casa que abriga essa organização se configura como um laboratório, onde são desenvolvidas práticas artístico-pedagógicas, a partir de experimentações criativas com crianças, adolescentes, jovens e adultos, moradores de comunidades situadas nas periferias de Salvador.

O caminho do CRIA sempre foi marcado pela busca de múltiplas possibilidades de educar, interagir e criar coletivamente.

Nesse caminhar, vamos, com uma equipe multidisciplinar de jovens e adultos, construindo e aperfeiçoando uma proposta educativa para e com crianças, adolescentes, jovens e adultos e também com suas referências parentais e comunitárias. No encontro, todos e todas estão completamente inseridos no processo educativo,

\footnotetext{
* CARLA LoPes é pedagoga é coordenadora geral de teatro do Centro de Referência Integral de Adolescentes - CRIA. IRENE PIÑEIRo é coordenadora da Área de Saúde e Direitos Sexuais e Reprodutivos do Centro de Referência Integral de Adolescentes - CRIA. $M \stackrel{a}{a}$ ELEONORA L. RABELLo é coordenadora do Centro de Referência Integral de Adolescentes - CRIA.
}

lidando com os desafios dos seus próprios processos de aprendizagem, das relações pessoais, da interação com os temas trabalhados e com as realidades nas quais operam socialmente.

A formação, no contexto do Programa de Educação para a Cidadania, é colocada em prática por meio de um currículo aberto e estruturada em três grandes eixos temáticos: educação, saúde e cultura. Também agrega as questões que emergem do cotidiano e da atuação comunitária dos jovens dinamizadores culturais e contribui para o desenvolvimento pessoal, para a construção de projetos de vida e para a constituição das identidades dos grupos artísticos partindo das questões chaves Quem sou eu? e Quem somos nós? - gerando a arte do CRIA, traduzida nas peças, nos recitais poéticos e, especialmente, na descoberta de cada pessoa que a casa abriga.

A formação também impulsiona a organização desses adolescentes, jovens e adultos que, agregados em grupos de atuação, constituem o que chamamos de CriaComunitário. Ele se revela nas ações dos dinamizadores culturais, nos seus territórios ${ }^{1}$ de atuação, com base em seus Planos de Atuação Comunitária.

O Programa de Educação para a Cidadania integra a dimensão da formação para a atuação comunitária em produção cultural, comunicação, cultura da infância, saúde e direitos sexuais e reprodutivos, articulação e mobilização social, entre outras áreas de conhecimentos e habilidades.

O CRIA é um espaço de questionamento, de educação para a autonomia ${ }^{2}$ de toda a sua equipe, que se percebe como um grupo coletivo disposto a participar e interagir com os novos grupos que são formados no contexto de seu Programa ou fora dele, com outras redes e movimentos sociais, para o desenvolvimento sustentável da sociedade. 

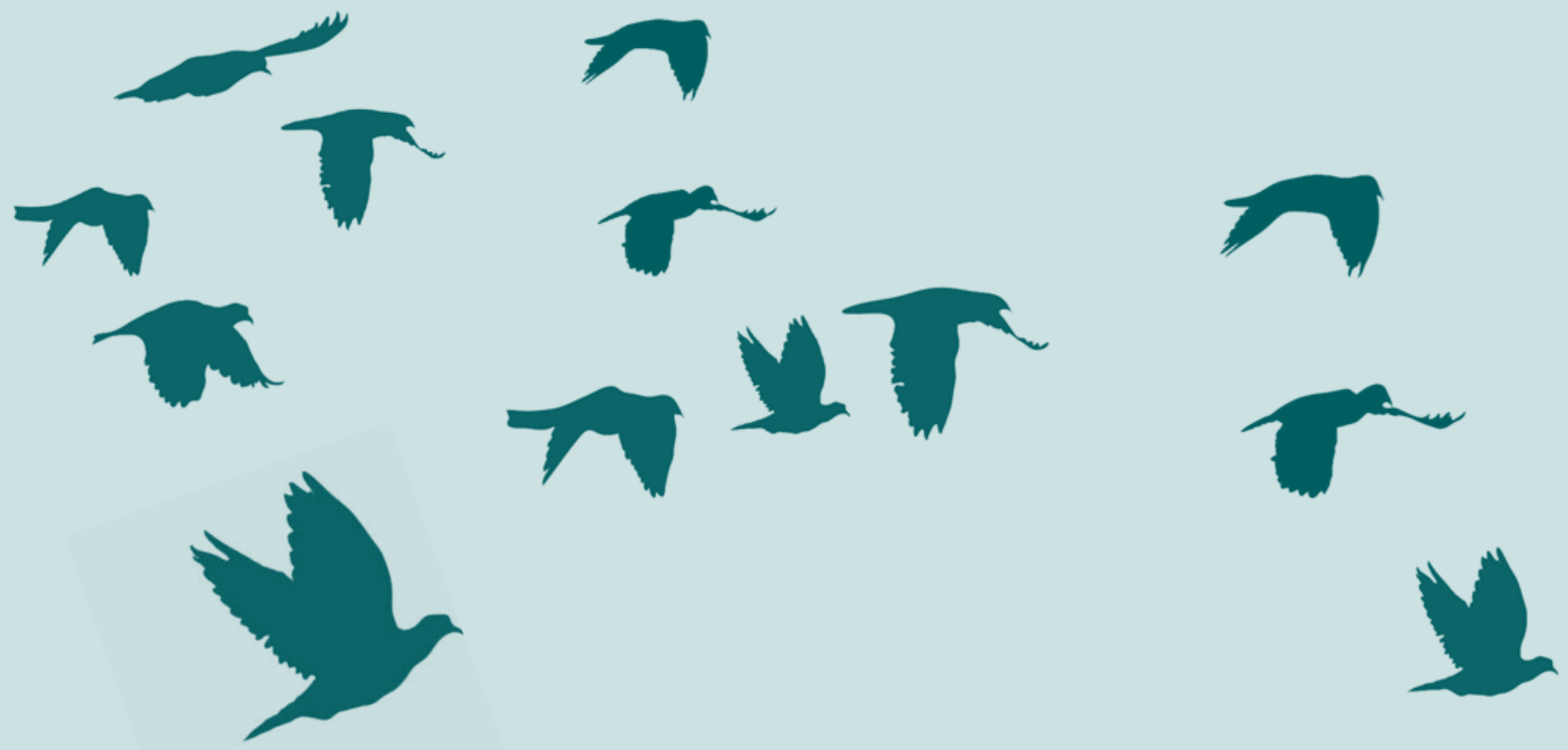

O exercício criativo, pautado na coletividade e na multiplicidade dos conhecimentos e habilidades de cada integrante, é constante e acontece nos encontros de formação, planejamento, acompanhamento e avaliação. Esse exercício dos grupos gestores do CRIA e do Programa de Educação para a Cidadania fortalece a sua vocação como uma casa de educação e como uma organização da sociedade civil, articuladora de redes de trocas e de construção de novos conhecimentos e de novas possibilidades.

A Rede Ser-tão Brasil $^{3}$ e a Rede Latino-Americana de Arte e Transformação Social ${ }^{4}$ são dois dos principais grupos de atuação e dinamização do CRIA.

Elas são tecidas por várias mãos de jovens e adultos que integram esses grupos, com um olhar aberto e sensivel para os mestres populares, para as culturas tradicionais e para a grande riqueza presente na diversidade cultural de nossas comunidades. Incorporamos a isso, diálogos criativos e transformadores, pautados na eqüidade, tomando a arte como expressão das suas culturas, do seu fazer e do seu desejo de transformação.

Na casa que abriga o CRIA, no Pelourinho, centro antigo de Salvador, encontra-se seu coração, como um laboratório acolhedor da diversidade e de múltiplas possibilidades. Ele é também um ponto a partir do qual tudo se irradia para as comunidades, cidades, redes e parcerias e para onde, depois, tudo converge, agregando novos saberes e aprendizados advindos dessas trocas, desses diálogos, fortalecendo e reafirmando a cada dia nossa missão institucional:

[...] provocar nas pessoas, por meio da arte-educação e do despertar de sensibilidades, atitudes transformadoras de si mesmas e da sociedade em que vivem, de forma coletiva e comunitária.

\section{A família na CASA}

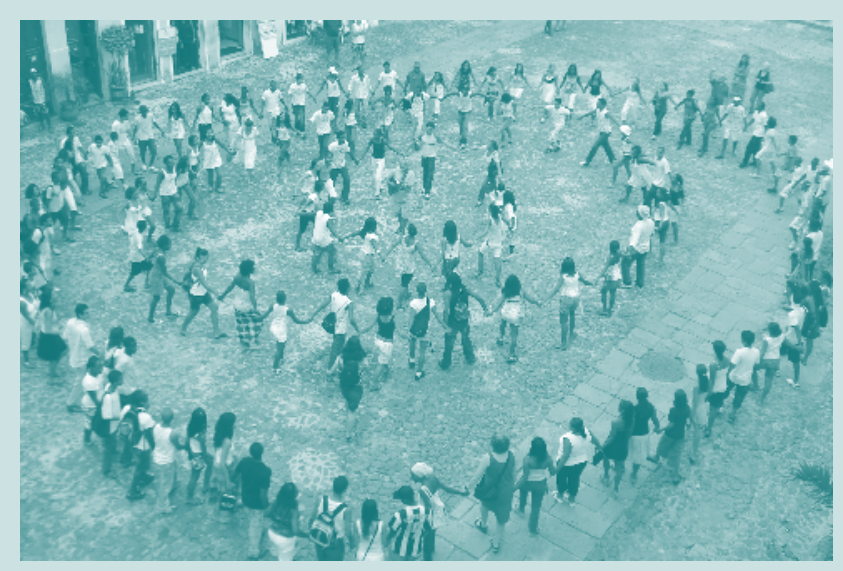

A família, ${ }^{5}$ nesta casa, tem seu lugar. Ela é o ponto central na experiência educativa do CRIA, sobretudo porque entendemos que, nas famílias, encontram-se os padrões que direcionam também a formação dos dinamizadores, e suas escolhas, interferindo na relação deles com o mundo, baseados em seus valores, normas, ritos e hierarquias.

Assim, no CRIA, a família é considerada um parceiro fundamental para a sustentabilidade institucional. É com ela que acompanhamos o desenvolvimento pessoal dos jovens, escutamos sua história, registramos suas opiniões e compreendemos a dinâmica familiar dos adolescentes, o que amplia nossas possibilidades de formação integral desses sujeitos.

A família participa do Programa de Educação para a Cidadania em diversos momentos. A tônica sempre é o encontro, a aproximação. Por intermédio do diálogo, 
buscamos juntos respostas para tantas indagações. Temos formações específicas para as famílias (cerca de seis a oito anuais), nas quais são debatidos temas elegidos pelo grupo, junto com a equipe do CRIA.

Nos últimos anos, foram priorizados temas relacionados à saúde e aos direitos sexuais e reprodutivos.

Nos ensaios abertos, quando são apresentados recitais poéticos e peças teatrais, as famílias são convidadas assisti-los e a opinar sobre eles para enriquecer o que se coloca em cena. Para quebrar mitos, preconceitos e estereótipos herdados dos pais, avós e aproximá-los dos que os filhos e filhas estão aprendendo, descobrindo. Além disso, trata-se de um espaço de troca de impressões sobre o desenvolvimento pessoal dos adolescentes.

Nos marcos festivos, como o São João, o Caruru de Cosme e Damião, o Natal, juntos, jovens, educadores, mães, pais e amigos louvam a alegria de estarem juntos, reinventando momentos mais brincantes e provocadores de trocas, diálogos e afetividades.

Também acontecem conversas individuais com as famílias ou com elas e os adolescentes, seja por uma solicitação dos educadores ou por uma demanda da família. Nessas conversas, são tratadas questões de conflitos familiares e/ou dificuldades específicas do adolescente,

O que é família? A peça Diálogos, criação coletiva encenada pelo grupo Pais e Filhos, ${ }^{6}$ define coletivamente família como:

[...] um composto de pessoas formado por pais, filhos, tios, tias, avós e tataravós. Pessoas unidas por vínculos sanguíneos ou não.

É esse conceito que orienta o nosso trabalho. Para estar no CRIA, são realizados alguns acordos entre o adolescente/jovem e a instituição e entre esta e a família. Um deles é que esse adolescente tenha uma "referência familiar". Na maioria das vezes, são mães, avós ou tias, mas estão presentes também madrinhas, vizinhas e amigas. Mulheres.

A idéia de família está geralmente relacionada a um parentesco (vínculos sanguíneos) ou, segundo o IBGE, a uma "unidade doméstica residencial".

Segundo o historiador francês Jean-Louis Flandrin, o conceito de família mais restrito, que relaciona parentesco com co-residência, não existia há poucos séculos. Somente a partir do final do século XVIII foi que essa definição ganhou força.
A família dos adolescentes que participam do CRIA não difere muito daquela apresentada nas pesquisas. Uma das características atuais da família refere-se à redução do número de filhos. Isso se deve à redução da taxa da fecundidade de mulheres adultas, hoje, com média de 2,7 filhos.

Notamos assim que a mulher tem conquistado outros espaços além da maternidade. Temos muitas famílias monoparentais chefiadas por mulheres, ${ }^{7}$ de classes populares, com baixa escolaridade, trabalhadoras domésticas, diaristas, do lar e/ou desempregadas.

A ausência do pai é freqüente. Em alguns casos, os/as filhos/as não conhecem seus pais. Às vezes, estes também não sabem que são pais. É a cultura do desconhecimento. No entanto, os homens também buscam novos lugares e papéis sociais. Permitem-se experimentar novas formas de vivência da masculinidade. Já se fala em masculinidades, no plural, para dar conta dessa diversidade do papel masculino. Assim, alguns vivenciam a paternidade de forma plena, embora em número muito reduzido.

Meu sonho é conhecer meu pai, me formar e ser respeitada.

Eliana, 15 anos/Grupo Pais e Filhos.

A mulher aparece como a grande referência familiar. Apesar de todo o processo de emancipação, com a conquista de direitos e a ocupação de espaços públicos, ela ainda é a rainha do lar, acumulando o que costumamos chamar de dupla jornada de trabalho. No entanto, essa nova mulher determinará modificações fundamentais na estrutura familiar.

De tanto falarmos em família e em famílias desestruturadas, avançamos para nos permitir interferir na constituição/construção de diferentes famílias, modificando assim uma das mais fortes e tradicionais instituições sociais, responsável pela reprodução dos valores vigentes, entre eles, o modelo patriarcal ainda predominante no Brasil.

0 aumento do número de separações, de re-casamentos, o reconhecimento do direito de casais homossexuais na adoção de crianças, um novo lugar social assumido pelo homem, são outros fatores que determinam novos arranjos familiares.

Essas mudanças no formato familiar não devem, no entanto, modificar a função dos pais de proteger, acalentar e 

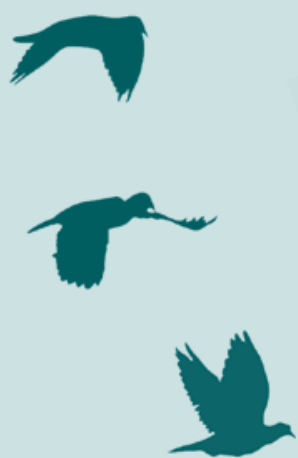

prover seus membros. $\mathrm{O}$ artigo 220 do Estatuto da Criança e do Adolescente - ECA afirma:

Aos pais, incumbe o dever de sustento, guarda e educação do filhos menores, cabendo-lhes ainda, no interesse destes, a obrigação de cumprir e fazer cumprir as determinações judiciais.

Por outro lado, o Estado assume compromissos com a família, como prega a Constituição Brasileira de 1998:

\section{Capítulo VII}

\section{Da família, da criança, do adolescente e do idoso}

\section{Art. 226.}

A família, base da sociedade, tem especial proteção do Estado. $\S 2$ - 0 casamento religioso tem efeito civil, nos termos da lei. $\S 3^{0}$ - Para efeito da proteção do Estado, é reconhecida a união estável entre o homem e a mulher como entidade familiar, devendo a lei facilitar sua conversão em casamento.

$\S 4^{\circ}$ - Entende-se, também, como entidade familiar a comunidade formada por qualquer dos pais e seus descendentes.

$\S 5^{\circ}$ - Os direitos e deveres referentes à sociedade conjugal são exercidos igualmente pelo homem e pela mulher.

$\S 8^{0}$ - O Estado assegurará a assistência à família na pessoa de cada um dos que a integram, criando mecanismos para coibir a violência no âmbito de suas relações.

\section{Art. 227.}

É dever da família, da sociedade e do Estado assegurar à criança e ao adolescente, com absoluta prioridade, o direito à vida, à saúde, à alimentação, à educação, ao lazer, à profissionalização, à cultura, à dignidade, ao respeito, à liberdade e à convivência familiar e comunitária, além de colocá-los a salvo de toda forma de negligência, discriminação, exploração, violência, crueldade e opressão.

Minha família é tão grande e tão pequena, e a minha tão complicada. Neste momento aqui com vocês, eu me sinto em casa. Agora, aqui no mundo, de um jeito ou de outro, somos um família.

Texto da peça Diálogos.

Em relação à mulher, essa referência familiar pertence a uma categoria de gênero que por si só a coloca em uma condição social desfavorável. Junte-se a isso, sua etnicidade (negras), classe social e grau de escolaridade e estamos diante de um quadro social bastante adverso.

Neste lugar de mulher e referência familiar, as mulheres assumem uma infinidade de tarefas, o que pode, em alguns casos, resultar em certa negligência em relação a seus fiIhos. Têm dificuldades em participar de reuniões e comemorações de escolas ou outros espaços de acompanhamento de formação dos adolescentes. Essa ausência é compreendida pelo adolescente como falta de amor, de cuidado.

Ser mulher é matar um leão todos os dias; é dormir e acordar num mundo cheio de preconceitos; isso é ser mulher... Mulher... anseios, desejos, expectativas, tabus, encontros e desencontros, medos, sonhos e fantasias... mulher, mulher, mulher... mães, filhas, tias, irmãs, avôs, buscas constantes. Projetos e sonhos a realizar, vontade de ser e de fazer, de se entregar e se soltar. Mas os desencontros traçam caminhos desconhecidos que se perdem com os desejos e fica a realizar [...]

Texto da peça Diálogos.

Entre outras pesquisas, a Gravad $/ 2004^{8}$ demonstra que, ao contrário do que diz o senso comum, que vê o adolescente como rebelde, em conflito com a família, esta é uma instituição fundamental para os adolescentes. Essa pesquisa evidencia que, ao lado da valorização da família, tornar-se mãe ou pai ainda se apresenta como um projeto de reconhecimento social.

Quero ser advogada, juíza ou promotora; meu maior medo é perder meus pais, pois amo minha família.

Daniela Oliveira, 12 anos/Grupo Pais e Filhos.

Os problemas de moradia enfrentados por essa população vão também influenciar no arranjo das famílias e suas relações. São conhecidos os puxadinhos/laje que mantêm a família próxima, não necessariamente unida. As relações de vizinhança, de solidariedade, a necessidade de estar junto, para sobreviver diante de uma série de adversidades, criam laços familiares, vínculos entre as mulheres. Assim, amigas e vizinhas se juntam a mães ou as substituem para responder às demandas da maternidade. Vemos então que, às vezes, torna-se necessário mais de uma mulher para dar conta desse papel. 
como espectadores, suas panelas e fazeres domésticos, e agora se tornaram "atrizes" junto com seus filhos, falando de seus direitos, questionando outras mulheres e homens sobre os papéis sociais à eles e à elas impostos, dançando, interpretando, despojando-se lindamente junto com outras pessoas no grupo.

Marias, Celestes, Marinalvas... mulheres negras, brancas índias... mães, muitas vezes pais, arrimos de família.

Trecho da peça Diálogos. Gislene Santana, 20 anos/Grupo Pais e Filhos.

Por meio do entendimento da criação, os componentes do grupo descobrem-se criativos, experimentando a troca de papéis, comportamentos, atitudes que ligam o belo ao fazer artístico. A arte tem missão diversa e, por isso, é sagrada; tem relação direta com a vida e nos permite reinventá-la.

Meu primeiro olhar para o mundo foi um pouco tarde, mas foi quando percebi que não era só mais uma no mundo.

Trecho da peça Diálogos.

Diz o ditado popular: "Quem casa, quer casa”. Porém, no contexto sociocultural em que vivem essas mulheres e meninas, esses homens e meninos, ao casarem e gerarem outras vidas, não encontram uma casa que possa abrigar suas angústias, medos, dúvidas.

Assim, o CRIA, ao assumir que é um lugar de referência para a educação de crianças, adolescentes e jovens e ao entender que a família e as referências parentais, consanguíneas ou não, são de fundamental importância como co-responsáveis por uma atenção integral à população infanto-juvenil, constitui-se também em uma casacoração que acolhe.

O CRIA procura, para eles e elas, uma educação para a constituição de sujeitos cidadãos e cidadãs comprometidos com o desenvolvimento pessoal de cada um e a construção de uma sociedade mais justa, bela e feliz.
HEILBORN, Maria Luíza. O Aprendizado da sexualidade: reprodução e trajetórias de jovens brasileiros. Rio de Janeiro: Garamond e Fiocruz, 2006.

KANT, Emanuel. Crítica da razão pura. Lisboa: Fundação Calouste Gulbenkian, 1985.

LINS, Daniel (Org.). A dominação masculina revisitada. Campinas: Papirus, 1998.

LOPES LOURO, Guacira. (Org). O Corpo educado: pedagogias da sexualidade. Belo Horizonte: Autêntica, 2001.

SANTOS, Milton. Por uma outra globalização: do pensamento único à consciência universal. Rio de Janeiro: Record, 2000.

Documentos Institucionais do CRIA.

\section{NOTAS}

1 Os territórios são antes relações sociais projetadas no espaço, que espaços concretos. Estes são apenas os substratos materiais das territorialidades. A territorialidade refere-se às relações de poder espacialmente delimitadas e operando sobre um substrato referencial (SANTOS, 1998).

2 Emanuel Kant foi quem definiu o conceito de autonomia na modernidade e fez dele um conceito central em sua teoria. Nesse ideal, viu o fundamento da dignidade humana e do respeito, o que foi central para o desenvolvimento dos sistemas legais, dos sistemas educacionais e da sociedade moderna como um todo. A concepção kantiana de liberdade como autodeterminação influenciou muito a educação e o modelo escolar criado a partir da modernidade.Paulo Freire, retomando o conceito de autonomia, traz uma contribuição extremamente importante para a educação, especialmente de países em que as situações de opressão são características marcantes, como é o caso do Brasil. Ele formulou uma proposta educacional que procura transformar o educando em sujeito, o que implica a promoção da autonomia.

3 A Rede Ser - Tão Brasil é uma articulação entre 17 grupos comunitários da cidade de Salvador e núcleos de arte-educação de 19 municípios baianos, inicialmente provocados pelo CRIA, que busca a transformação social por meio da arte, revelando novas formas de desenvolvimento local baseadas na expressão das culturas tradicionais.

4 A Rede Latino -Americana de Arte e Transformação Social é formada por 24 organizações de sete países da América Latina: Brasil, Chile, Argentina, Bolívia, Costa Rica, Guatemala e Peru. É uma articulação de um conjunto de iniciativas que realizam, na América Latina, práticas artísticas de qualidade em torno da geração de uma cidadania efetiva, integração social, promoção dos direitos humanos, interculturalidade e sustentabilidade social global.

5 No CRIA, qualquer referência parental ou de vizinhança responsável é considerada família. Aquela pessoa que se dispõe, no diálogo com o CRIA, a acompanhar, cuidar, se co-responsabilizar pelas crianças, adolescentes e jovens que integram o Programa de Educação para a Cidadania.

6 O CRIA tem um repertório artístico composto de cinco peças educativas, recital poético e um grupo de clown. O Grupo Pais e Filhos foi formado em 2000 , sendo composto por duplas familiare e surgiu para ressaltar a importância do diálogo na família para a conquista de relações mais igualitárias entre homens e mulheres.

7 O dado mais recente do IBGE informa que $29,2 \%$ dos lares são chefiados por mulheres.

8 Gravidez na Adolescência: estudo multicêntrico sobre jovens, sexualidade e reprodução no Brasil. Pesquisa realizada entre outubro de 2001 e janeiro de 2002 sobre a população juvenil em três municípios: Porto Alegre, Rio de janeiro e Salvador.

\section{REFERÊNCIAS}

ÁRIES, Philippe. Historia social da criança e da famíla. Rio de Janeiro: LTC, 2006. DEL PRIORE, Mary (Org.). História das mulheres no Brasil. São Paulo: Contexto, 2006. GADOTTI, M. Lições de Freire. São Paulo: Faculdade de Educação, v. 23, n. 1-2, jan. dez., 1997. 
